\title{
Effect of Periodontal Treatment in Renal Transplant Recipients
}

\author{
Ana Pejcic ${ }^{a}$ Vidojko Djordjevic ${ }^{b}$ Draginja Kojovic $^{a}$ Vesna Zivkovic $^{c}$ \\ Ivan Minic ${ }^{a}$ Dimitrije Mirkovic ${ }^{e}$ Mariola Stojanovic $^{d}$ \\ ${ }^{a}$ Department of Periodontology and Oral Medicine, ${ }^{b}$ Clinic of Nephrology, ${ }^{C}$ Institute of Pathology, and ${ }^{d}$ Institute for \\ Public Health, Medical Faculty, University of Nis, and ePrivate Practice 'Smile-Dent', Nis, Serbia
}

\section{Key Words}

Gingival overgrowth · Periodontal treatment · Cyclosporine

\begin{abstract}
Objective: To evaluate the effect of periodontal treatment on gingival overgrowth in a group of renal transplant patients. Subjects and Methods: Twenty-five renal transplant recipients receiving immunosuppressive therapy with cyclosporine A ( $C s A)$ were randomly assigned to 2 groups. Group $1(n=15)$ included patients who had been specifically referred to a dental clinic to prevent gingival overgrowth and were given full periodontal therapy. Group $2(n=10)$ was comprised of patients who did not receive any professional periodontal cleaning. Patients from both groups were examined to determine their periodontal status before and after 3,6 and 12 months in terms of their plaque index, gingival index and gingival overgrowth. During the examination, their overall health was stable. Results: For group 1, the scores were 1.89 (baseline), 0.98 (6 months) and 0.56 (12 months), and hence there were significant reductions ( $p=$ 0.0001). The gingival indices were 1.71 (baseline), 0.76 (6 months) and 0.35 (12 months), and the reductions were also significant ( $p=0.0001)$. A significant association was observed between poor oral hygiene and the degree of gingival overgrowth. The 1-year post-treatment follow-up
\end{abstract}

\begin{tabular}{ll}
\hline KARGER & $\begin{array}{l}\text { ( } 2013 \text { S. Karger AG, Basel } \\
1011-7571 / 13 / 0232-0149 \$ 38.00 / 0\end{array}$ \\
E-Mail karger@karger.com & $\begin{array}{l}\text { This is an Open Access article licensed under the terms of the } \\
\text { www.karger.com/mpp }\end{array}$ \\
$\begin{array}{l}\text { Creative Commons Attribution-NonCommercial 3.0 Un- } \\
\text { ported license (CC BY-NC) (www.karger.com/OA-license), } \\
\text { applicable to the online version of the article only. Distribu- } \\
\text { tion permitted for non-commercial purposes only. }\end{array}$
\end{tabular}

showed that patients in group 1 did not develop gingival overgrowth due to the use of CsA as group 2 did without prior periodontal therapy. Conclusion: Oral hygiene status was the most important variable related to the development and degree of gingival overgrowth due to the use of CsA.

(c) 2013 S. Karger AG, Basel

\section{Introduction}

Gingival overgrowth (GO) is one of the most important clinical features of gingival pathology. It has multifactorial aetiologies and has been frequently associated with inflammatory changes in the gingiva. Other factors related to this condition are hereditary (familial) characteristics, malignancies and adverse effects associated with the systemic administration of certain drugs [1]. Drug-induced GO remains a significant problem for dental clinicians and periodontologists. Patients medicated with certain drugs may develop this side effect which may interfere with aesthetics, mastication or speech [2]. Disfiguring GO triggered by these medications is not only aesthetically displeasing but also often impairs nutrition and access for oral hygiene, resulting in increased susceptibility to oral infection, caries and periodontal diseases [3]. 
An increasing number of medications are associated with GO. These include over 20 medications from 3 pharmaceutical categories, i.e. anticonvulsants, calcium channel blockers and immunosuppressants [4].

Cyclosporine, a potent immunosuppressant, has significantly reduced the morbidity and mortality rates associated with solid-organ transplantations. The major side effect of this drug in the oral cavity is gingival enlargement. Cyclosporine-induced gingival enlargement has been reported by different transplant centres as varying from 7 to $80 \%$ [4]. Many factors related to cyclosporine-induced GO have been investigated [2]. However, controversy still exists. It has been suggested that the incidence and severity of GO in patients undergoing cyclosporine $\mathrm{A}$ (CsA) immunosuppressant therapy is dependent on their genetic disposition as well as local and pharmacological factors affecting the patient [5]. The treatment of GO must focus on the prevention of known predisposing factors such as plaque accumulation as reported in cyclosporine-induced overgrowth $[5,6]$.

The aim of this study was to conduct a longitudinal evaluation of the incidence and severity of GO induced by immunosuppressive agents and to assess the effectiveness of periodontal therapy in cyclosporine-induced GO, including the CsA dose, the duration of CsA therapy and the dose of prednisolone and azathioprine.

\section{Subjects and Methods}

This study included 25 volunteer renal transplant recipients (14 men and 11 women; age 35-46 years) who had undergone kidney transplantation at the Medical Clinical Center (Nis, Serbia). The immunosuppressive therapy consisted of a triple regimen of azathioprine, corticosteroids and CsA. After renal transplantation, all subjects received $<5 \mathrm{mg} / \mathrm{kg}$ cyclosporine as an immunosuppressant agent. At the time of the initial presentation, the patients were medically stable. Renal transplants were functional and showed no signs of rejection. None of the patients had undergone periodontal therapy 6 months before the transplantation. Patient consent was obtained. All of the clinical evaluations and treatments were conducted under appropriate antibiotic prophylaxis (e.g. erythromycin). This study was approved by the Ethics Committee of the Medical Faculty of the University of Nis.

The patients were randomized into 2 study groups before they started to develop overgrowth. Fifteen patients ( 6 males and 9 females) were assigned to group 1 and received periodontal treatment as described below. All of the patients were trained in oral hygiene techniques (brushing and flossing) and participated in an oral hygiene motivation programme. The treatment of the patients began with a non-surgical approach and consisted of scaling and root planning to eliminate local factors and reduce gingival inflammation. The patient was instructed to maintain good oral hygiene with the use of chlorhexidine oral rinses. A commercially available chlorhexidine rinse $(0.12 \%)$ was used to help control plaque accumulation and to reduce the development of gingival inflammation. After periodontal therapy, the patients received periodical maintenance every 3 months.

The 10 patients assigned to group 2 (control; 4 males and $6 \mathrm{fe}$ males) did not receive any periodontal treatment because they did not respond to the appeal for preventive treatment of periodontal disease. The patients' periodontal condition was determined by a periodontologist (D.M.) while they were in the Department of $\mathrm{Ne}$ phrology of the Medical Clinical Center.

The patients' physicians were consulted regarding periodontal problems and the recommended periodontal treatment plan for both groups. After transplantation, a complete oral examination was performed on all patients by the same examiner (D.M.). The examined data included the plaque score, the gingival index (GI) and the GO measured in millimetres. In the third month after transplantation, a complete periodontal examination was performed before the patients started to develop overgrowth. The same data were examined after 6 and 12 months. Periodontal disease was defined as a mean pocket depth of more than $3 \mathrm{~mm}$ measured with a periodontal probe (Michigan 0). Demographic data and periodontal clinical parameters [plaque index (PLI), GI and GO] were examined at 6- and 12-months intervals. The following clinical parameters were measured: the PLI - teeth were stained and PLI values were determined according to the method of Nyman et al. [7]; the GI score - this was also measured according to the procedure of Nyman et al. [7], and GO - the average extent of GO in millimetres was determined by inserting a periodontal probe (Michigan 0 ) at 3 vestibular points (mesial, midpoint and distal) for each tooth and the extent of GO was measured from the cemento-enamel junction to the crest of the gingival margin.

\section{Statistical Analysis}

A t test for independent samples was used to test group 1 compared to group 2 (tested on drugs and age) and a non-parametric Mann-Whitney test was used for 2 independent samples (testing PLI, GI and GO). A non-parametric Friedman test was used to test parameters of time (non-parametric test for repeated measures for related samples).

\section{Results}

The demographic and clinical periodontal parameters are presented in table 1 . Patients in the test and control groups were not statistically ( $p>0.05)$ different in terms of age, current CsA dose, duration of CsA therapy or current dose of prednisolone and azathioprine. Moreover, at the initial examination (after 3 months) there were no significant differences between periodontal parameters in both groups.

The periodontal parameters 3, 6 and 12 months after therapy showed that patients who underwent an initial professional cleaning (group 1) did not have gingival en- 
Table 1. Demographic and clinical periodontal parameters in renal transplant patients

\begin{tabular}{lccc}
\hline Variables & $\begin{array}{l}\text { Test group } \\
(\mathrm{n}=15)\end{array}$ & $\begin{array}{l}\text { Control group } \\
(\mathrm{n}=10)\end{array}$ & $\mathrm{p}$ value \\
\hline Gender, $\mathrm{n}$ & & & \\
$\quad$ Male & 6 & 6 & \\
$\quad$ Female & 9 & $39.4 \pm 2.072$ & $>0.05$ \\
Mean age \pm SD, years & $40.4 \pm 3.75$ & $1.98 \pm 0.224$ & $>0.05$ \\
Mean PLI \pm SD & $1.89 \pm 0.753$ & $1.72 \pm 0.415$ & $>0.05$ \\
Mean GI \pm SD & $1.71 \pm 0.483$ & $3.5 \pm 0.538$ & $>0.05$ \\
Mean GO \pm SD, mm & $3.55 \pm 0.828$ & $181.2 \pm 14.303$ & $>0.05$ \\
Mean current CsA dose \pm SD, mg/day & $187.1 \pm 42.106$ & $8.1 \pm 1.475$ & $>0.05$ \\
Mean current prednisolone dose \pm SD, mg/day & $8.25 \pm 1.3591$ & $70 \pm 14.577$ & $>0.05$ \\
Mean current azathioprine dose \pm SD, mg/day & $76.5 \pm 13.344$ & 12 & \\
Duration of CsA therapy, months & 12 & & \\
\hline
\end{tabular}

Table 2. Periodontal parameters in renal transplant patients 3, 6 and 12 months after periodontal therapy

\begin{tabular}{|c|c|c|c|c|c|c|c|c|}
\hline \multirow[t]{2}{*}{ Variables } & \multicolumn{3}{|l|}{ Test group } & \multirow[t]{2}{*}{$\mathrm{p}$ value } & \multicolumn{3}{|c|}{ Control group } & \multirow[t]{2}{*}{$\mathrm{p}$ value } \\
\hline & 3 months & 6 months & 12 months & & 3 months & 6 months & 12 months & \\
\hline PLI & 1.89 & 0.978 & 0.56 & $<0.0001$ & 1.98 & 1.98 & 1.86 & $>0.05$ \\
\hline GI & 1.71 & 0.76 & 0.35 & $<0.0001$ & 1.72 & 1.80 & 1.82 & $>0.05$ \\
\hline $\mathrm{GO}$ & 3.55 & 3.39 & 2.65 & $<0.0001$ & 3.5 & 4.06 & 5.12 & $<0.001$ \\
\hline
\end{tabular}

largement after transplantation compared to the control group $(\mathrm{p}>0.05)$. There was a reduction in periodontal clinical parameters in relation to the duration of immunosuppressive therapy. PLI scores were reduced from 1.89 to $0.56(\mathrm{p}<0.0001)$ and the GI decreased from 1.71 to $0.35(\mathrm{p}<0.0001)$ in group 1 . A dramatic response was noticed after 12 months of maintenance of regular oral hygiene.

In the control group, the PLI, GI and GO were significantly higher $(\mathrm{p}<0.001)$ than in the test group (table 2$)$. There was a positive association between the severity of GO and gingival inflammation and the plaque score. In the control group of patients with GO, the PLI and GI were greater than observed in the other group. An increased tendency toward gingival enlargement was found at the immediate post-transplant examination 6 months after renal transplantation. Gingival enlargement was significantly related to the PLI at each time point until 12 months after renal transplantation $(\mathrm{p}<0.0001)$. The results showed that the cyclosporine-induced gingival enlargement of these patients was not statistically associated with age or gender $(\mathrm{p}>0.05)$.

GO and Renal Transplantation

\section{Discussion}

The findings of this study support the hypothesis that plaque is a significant contributing factor in the development of cyclosporine-induced GO. The results further show that, in patients without periodontal therapy, complications of cyclosporine had adverse effects on oral and periodontal health due to the development of clinical GO in contrast to patients who had periodontal treatment. This might suggest that the treatment had an influence on cyclosporine-induced GO.

The importance of plaque as a cofactor in the aetiology of drug-associated GO is recognized in the most recent classification system for periodontal diseases $[8,9]$. In this classification, 'drug-influenced gingival overgrowth' is categorized as plaque-induced gingival diseases modified by medications $[8,9]$. Several authors have reported an association between plaque indices and the prevalence and severity of cyclosporine-induced and nifedipine-induced GO [10-14]. In transplant patients, the ideal treatment for drug-related GO is to change the medication; however, drug substitution or cessation may not be an option due to the risk of transplant rejection. The treat- 
ment of gingival enlargement in patients taking CsA should focus on their chronic immunosuppression. The severity of the enlargement is often proportional to the amount of gingival inflammation present, as confirmed in this study, and not the dosage of medication. The dose and duration of medication was unchanged during the investigation in both groups and their effects did not affect the results. Oral hygiene and periodic maintenance without any change in medication was relatively successful in controlling the degree of enlargement [15]. A 3-month periodontal maintenance interval is strongly recommended for patients taking drugs associated with gingival enlargement [16]. While excellent oral hygiene and professional plaque control can potentially prevent or lessen the severity of the condition, they are often insufficient for reversing the process once it is established [10].

The positive correlation of GO (induced by CsA) to GI and PLI scores in this study confirmed the results of previous studies $[17,18]$. The decrease in both plaque and GI in the test group during the study period could be due to the oral hygiene training and motivation programme as previously reported [19].

Topical anti-inflammatory agents are usually successful in providing symptomatic relief. Recent reports in the literature indicate that chlorhexidine in addition to controlling dental plaque also helps control gingival inflammation [20-22]. The treatment aspects include: phase 1 therapy, substitution of the drug, surgical excision and maintenance and supportive therapy resulting in excellent clinical outcomes [23, 24].

The improvements obtained via antibiotic use may not be permanent, especially when a fibrous GO is involved. Antibiotic therapy for these indications can be used as an adjunct to conventional mechanical treatment to reduce the signs of inflammation; thereafter, a surgical intervention can be performed if the general condition of the patient allows.
For all of these reasons, the periodontologist should minimize gingival infection through optimal plaque control and frequent periodontal maintenance as the first step in the prevention of drug-induced GO. Recurrences are frequent, particularly in patients with less-than-optimal plaque control and when the drug regimens cannot be modified or reduced [1]. Other studies $[9,25]$ have shown an increase in GO in patients who did and did not undergo periodontal treatment prior to CsA therapy. A probable explanation could be that our study was conducted in a period of near stabilization in which the impact of periodontal treatment was isolated from other changes.

Dental plaque has been suggested as a causative cofactor [26] of gingival enlargement. There have been reports that poor oral hygiene exacerbates drug-induced GO and that oral hygiene measures may reduce the degree of overgrowth, but they do not inhibit its development [27, $28]$. It has been suggested that cyclosporine affects the metabolic function of fibroblasts (e.g. collagen synthesis, breakdown). The increased levels of interleukin- 6 and the decreased levels of interferon observed during CsA therapy may favour the fibroblast synthesis of collagen [29, 30].

\section{Conclusions}

Since there was no GO after periodontal treatment in patients who were administered CsA after renal transplantation, it seems that dental plaque control is the best prevention for GO. Good oral hygiene is the most important variable related to the development and degree of GO due to the use of CsA, so regular control could help prevent GO.

\section{References}

1 Bhatia V, Mittal A, Parida AK, et al: Amlodipine induced gingival hyperplasia: a rare entity. Int J Cardiol 2007;122:23-24.

2 Adams D, Davies G: Gingival hyperplasia associated with cyclosporin: a report of two cases. Br Dent J 1984;157:89-90.

3 Lafzi A, Farahani RM, Shoja MA: Amlodipine-induced gingival hyperplasia. Med Oral Patol Oral Cir Bucal 2006;11:480-482.
-4 Dongari-Bagtzoglou A; Research, Science and Therapy Committee, American Academy of Periodontology: Drug-associated gingival enlargement. J Periodontol 2004;75:1424-1431.

5 Cebeci I, Kantarci A, Firath E, et al: The effect of verapamil on the prevalence and severity of cyclosporine-induced gingival overgrowth in renal allograft recipients. J Periodontol 1996; 67:1201-1205.
6 Somacarrera LM, Lucas M, Barrios C: Effectiveness of periodontal treatments on cyclosporine-induced gingival overgrowth in transplant patients. Br Dent J 1997;183:8994.

7 Nyman S, Lindhe J, Lindhe J (eds): Clinical Periodontology and Implant Dentistry. Copenhagen, Blackwell Munksgaard, 2000, pp 403-413. 
8 Seymour RA, Smith DG: The effect of a plaque control program on the incidence and severity of cyclosporine-induced gingival changes. J Clin Periodontol 1991;18:107-110.

-9 Armitage GC: Development of a classification system for periodontal diseases and conditions. Ann Periodontol 1999;4:1-6.

10 Bullon P, Machuca G, Martinez-Sauquillo A, et al: Evaluation of gingival and periodontal conditions following causal periodontal treatment in patients treated with nifedipine and diltiazem. J Clin Periodontol 1996;23:649657.

11 Paixão CG, Sekiguchi RT, Saraiva L, et al: Gingival overgrowth among patients medicated with cyclosporine A and tacrolimus undergoing renal transplantation: a prospective study. J Periodontol 2011;82:251-258.

12 Cota LO, Aquino DR, Franco GC, et al: Gingival overgrowth in subjects under immunosuppressive regimens based on cyclosporine, tacrolimus, or sirolimus. J Clin Periodontol 2010;37:894-902.

-13 Bryan RB, Sullivan SM: Management of dental patients with seizure disorders. Dent Clin North Am 2006;50:607-623.

14 Mavrogiannis M, Ellis JS, Thomason JM, et al: The management of drug-induced gingival overgrowth. J Clin Periodontol 2006;33:434439.

15 Nishikawa S, Tada H, Hamasaki A, et al: Nifedipine-induced gingival hyperplasia: a clinical and in vitro study. J Periodontol 1991;62: 30-35.
16 Montebugnoli L, Servidio D, Bernardi F: The role of time in reducing gingival overgrowth in heart-transplanted patients following cyclosporine therapy. J Clin Periodontol 2000; 27:611-614.

17 Argani H, Pourabbas R, Hassanzadeh D, et al: Treatment of cyclosporine-induced gingival overgrowth with azithromycin-containing toothpaste. Exp Clin Transplant 2006;4:420 424.

18 Hall EE: Prevention and treatment considerations in patients with drug-induced gingival enlargement. Curr Opin Periodontol 1997;4: 59-63.

19 Strachan D, Burton I, Pearson GJ: Is oral azithromycin effective for the treatment of cyclosporine-induced gingival hyperplasia in cardiac transplant recipients? J Clin Pharm Ther 2003;28:329-338.

20 Persson RE, Truelove EL, LeResch L, et al: Therapeutic effects of daily or weekly chlorhexidine rising on oral health of a geriatric population. Oral Surg Oral Med Oral Pathol 1991;72:184-191.

21 Pejcic A: Comparative Analysis of Low Level Laser Therapy and Conservative Treatment of Inflamed Gingiva; master's thesis, University of Nis, Nis, 2005.
22 Ramalho VL, Ramalho HJ, Cipullo JP, et al: Comparison of azithromycin and oral hygiene program in the treatment of cyclosporine-induced gingival hyperplasia. Ren Fail 2007;29:265-270.

23 Triveni MG, Rudrakshi C, Mehta DS: Amlodipine-induced gingival overgrowth. J Indian Soc Periodontol 2009; 13:160-163.

24 Walker CB, Gordon JM, Magnusson I, et al: A role for antibiotics in the treatment of refractory periodontitis. J Periodontol 1993;64: 772-781.

25 Kwun WH, Suh BY, Kwun KB: Effect of azithromycin in the treatment of cyclosporine-induced gingival hyperplasia in renal transplant recipients. Transplant Proc 2003; 35:311-312.

26 Brown RS, Beaver WT, Bottomley WK: On the mechanism of drug-induced gingival hyperplasia. J Oral Pathol Med 1991;20:201209.

27 Devanna R, Asif K: Interdisciplinary management of a patient with a drug-induced gingival hyperplasia. Contemp Clin Dent 2010;1: 171-176.

28 Lafzi A, Farahani RMZ, Shoja MAM: Phenobarbital-induced gingival hyperplasia. J Contemp Dent Pract 2007;6:50-56.

29 Bulut S, Ozdemir BH: Apoptosis and expression of caspace-3 in cyclosporine-induced gingival overgrowth. J Periodontol 2007;78: 2364-2368

>30 Dongari-Bagtzoglou A: Drug-associated gingival enlargement. J Periodontol 2004;75: 1424-1431. 